\title{
Corrigendum: Characterization of T-bet and Eomes in Peripheral Human Immune Cells
}

\author{
James J. Knox ${ }^{1}$, Gabriela L. Cosma ${ }^{2}$, Michael R. Betts ${ }^{1 *}$ and Laura M. McLane ${ }^{1 *}$ \\ ${ }^{1}$ Department of Microbiology, Perelman Institute for Immunology, University of Pennsylvania, Philadelphia, PA, USA, \\ ${ }^{2}$ Department of Immunology, Thomas Jefferson University, Philadelphia, PA, USA
}

Keywords: T-box transcription factors, T-cells, NK cells, B-cells, T-bet

\section{A corrigendum on}

Characterization of T-bet and Eomes in Peripheral Human Immune Cells

by Knox JJ, Cosma GL, Betts MR, McLane LM. Front Immunol (2014) 5:217. doi: 10.3389/ fimmu.2014.00217

The corrigendum regards data and text for the final figure of the manuscript, Figure 7:

Subsequent analysis of T-bet levels in human lymphocytes comparing different permeabilization procedures (eBioscience FoxP3 transcription factor kit, BD Pharmingen Cytofix/Cytoperm) has revealed variable findings in the level of T-bet expression detected within certain lymphocyte

\section{OPEN ACCESS}

Edited by:

Bruno Laugel,

Cardiff University, UK

Reviewed by:

David K. Cole,

Cardiff University, UK

*Correspondence:

Michael R. Betts

betts@mail.med.upenn.edu;

Laura M. McLane

Imclane@mail.med.upenn.edu

Specialty section:

This article was submitted to T Cell Biology,

a section of the journal

Frontiers in Immunology

Received: 10 August 2016

Accepted: 22 August 2016 Published: 08 September 2016

Citation:

Knox JJ, Cosma GL, Betts MR and

McLane LM (2016) Corrigendum: Characterization of T-bet and Eomes in Peripheral Human Immune Cells.

Front. Immunol. 7:337. doi: 10.3389/fimmu.2016.00337 populations. While this does not change our conclusions for the majority of the populations assessed in this study, B cells in particular show differences under these conditions. Specifically, permeabilization via the eBioscience FoxP3 transcription factor staining buffer set indicates that subpopulations of memory B cells express significantly higher levels of T-bet (MFI) compared to plasmablasts, and that plasmablasts express T-bet only at low levels. Subsequent RNA transcript analysis confirms that plasmablasts express T-bet RNA at a level comparable to naïve B cells. Together, in combination with fluorescence-minus-one and isotype control studies, these new findings suggest that subsets memory B cells, not plasmablasts, express the highest levels of T-bet in the B cell compartment and plasmablasts express T-bet at a lower frequency than is reported in Figure 7.

Figure 7 Legend should read:

(C) Histograms depicting T-bet expression levels in B-cells and NK cells from a representative donor. Histograms represent the following subsets: naïve B-cells (thick black line), memory B-cells (shaded gray), plasmablasts (thin black line), CD56 $6^{\text {bright }} \mathrm{NK}$ cells (gray line), and CD56 $6^{\text {dim }} \mathrm{NK}$ cells (shaded black).

B-cell results section should be titled "T-bet is predominantly expressed in mature memory B-cells" and should read:

While Eomes was undetectable in B-cells (data not shown), we found T-bet in $\sim 10 \%$ of B-cells (Figure 7B). This T-bet expression was largely relegated to memory B-cells, with significantly lower amounts observed in transitional/immature B-cells, naïve B-cells, and plasmablasts (Figure 7B). Greater than $15 \%$ of memory B-cells expressed T-bet, a significantly higher frequency than that of all other B-cell populations, suggesting that T-bet may play a particularly important role in memory B-cell function.

The discussion related to T-bet expression in plasmablasts should be reconsidered as follows:

We found that T-bet is not significantly expressed in transitional/immature B-cells, naïve B-cells, and plasmablasts, but is highly expressed in subsets of memory-B cells. Reduced frequencies of T-bet expression in plasmablasts indicate a specific role for T-bet at the memory B-cell stage of development, which may no longer be necessary after further differentiation to the plasmablast stage. 


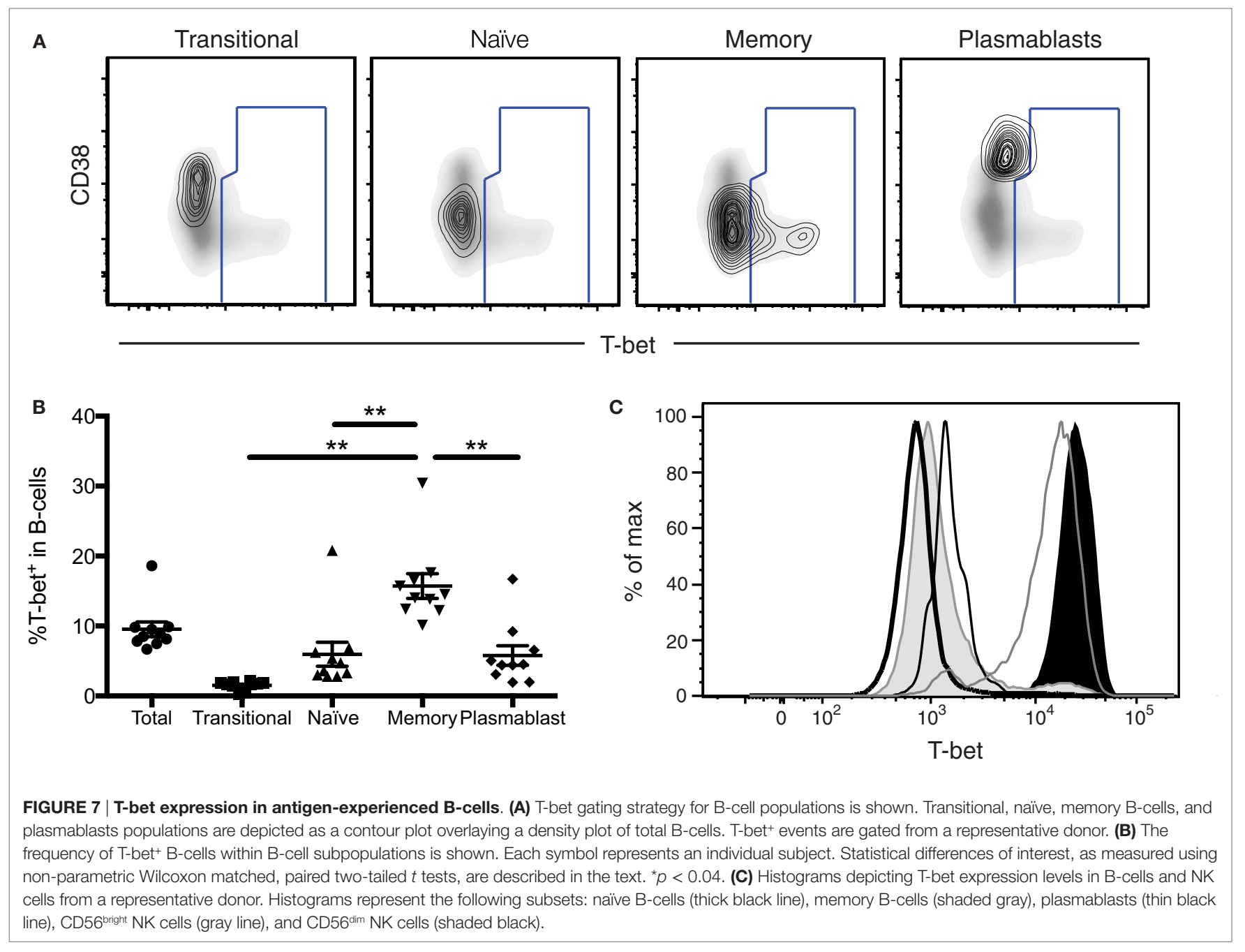

Conflict of Interest Statement: The authors declare that the research was conducted in the absence of any commercial or financial relationships that could be construed as a potential conflict of interest.

Copyright (c) 2016 Knox, Cosma, Betts and McLane. This is an open-access article distributed under the terms of the Creative Commons Attribution License
(CC BY). The use, distribution or reproduction in other forums is permitted, provided the original author(s) or licensor are credited and that the original publication in this journal is cited, in accordance with accepted academic practice. No use, distribution or reproduction is permitted which does not comply with these terms. 